\title{
LABORATORY DIAGNOSIS
}

\section{Rapid Diagnosis of Genital Tuberculosis by Real-time Polymerase Chain Reaction}

\author{
Bharti Malhotra, Parul Sinha, Saroj Hooja, Leela Vyas
}

\begin{abstract}
Objective: Rapid diagnosis of genital tuberculosis (GTB) is essential as it is an important cause of infertility among women. Diagnosis can be done by imaging techniques, direct visualization by endoscopy, serology, histopathology, culture and polymerase chain reaction (PCR) tests. Laparoscopy detects macroscopic changes only; histology is only suggestive and not confirmatory unless acid fast bacilli (AFB) are demonstrated in the lesion but sensitivity is poor in paucibacillary disease. Culture methods are the gold standard but slow growth of most pathogenic mycobacteria delays the diagnosis. PCR can rapidly detect even few copies of DNA with high sensitivity and specificity.
\end{abstract}

Aim: Comparative evaluation of AFB smear examination, culture in Middlebrook 7H9 media and IS6110 based real-time PCR assay for the detection of mycobacteria in various female genital samples.

Materials and methods: A total of 555 female genital samples like endometrial and fallopian tube biopsies, menstrual blood and vaginal discharge were processed by modified Petroff's method. The deposit was used for detection of mycobacteria by AFB smear, culture on Middlebrook 7H9 media and IS6110 based real-time PCR.

Results: Out of 555 samples, $25.22 \%$ (140/555) were positive by the combination of all the methods used. Overall positivity by real-time PCR alone was $23.78 \%$ (132/555), by culture $8.28 \%$ $(46 / 555)$ and $2.70 \%(15 / 555)$ by AFB smear examination. Out of total positives, $94.28 \%$ (132/140) were positive by PCR alone, $32.85 \%(46 / 140)$ by culture and $10.71 \%(15 / 140)$ by AFB smear. Eight $(5.71 \%)$ culture positive samples were negative by smear and PCR, six of these were nontubercular mycobacteria (NTM) and two samples had PCR inhibitors as confirmed by spiking with positive DNA. Contamination was observed in 25/555 $(4.5 \%)$ which were reported negative by culture but three of these were PCR positive. AFB smear results were available in 1 hour, PCR in 1 day and culture in 4 to 6 weeks.

Conclusion: PCR was found to be the most rapid and sensitive (94.28\%) method, 9-fold more sensitive than smear examination and 3-fold than the culture for detection of mycobacteria. Results were available in 4 to 6 weeks time for culture but in only 1 day by PCR. IS6110 PCR can detect only MTB and not the NTM. Use of multiplex PCR with genus and MTB specific primers will increase the sensitivity of test but care needs to be taken to prevent false positivity due to cross contamination and false negative due to PCR inhibitors.

Keywords: Infertility, Genital TB, Real-time PCR, AFB smear.

How to cite this article: Malhotra B, Sinha P, Hooja S, Vyas L. Rapid Diagnosis of Genital Tuberculosis by Real-time Polymerase Chain Reaction. J South Asian Feder Obst Gynae 2012;4(1):39-42.

Source of support: Nil

Conflict of interest: None declared

\section{INTRODUCTION}

The global prevalence of genital tuberculosis (GTB) is estimated to be 8 to 10 million cases, with a rising incidence in the industrialized and developing countries partly as a result of its association with HIV virus infection. ${ }^{1}$ It is the root cause in about 5 to $16 \%$ of cases of infertility among Indian women, though the actual incidence may be underreported due to asymptomatic presentation of GTB and paucity of investigations. $^{2,3}$ GTB should always be considered as a probable cause in the diagnostic work-up of infertile couples, especially in populations with a high prevalence of TB - even in the absence of a previous history of TB. GTB is a diagnosis, based on the collective evidences from imaging techniques, direct visualization by endoscopy, serology, histopathology of material from genital tract, culture and polymerase chain reaction (PCR) tests. ${ }^{1}$

Laparoscopy generally detects macroscopic changes, such as peritubal adhesions, tubercles on the tubes and small tuboovarian masses that commonly are seen in chronic cases, GTB presents unique diagnostic challenges including subtle clinical manifestations that may be overlooked in laparoscopy during early stages of infection. ${ }^{4}$ Histological diagnosis from tissue examination is only suggestive and not confirmatory unless acid fast bacilli (AFB) are demonstrated in the lesion. ${ }^{5}$ Culture methods are still the gold standard in the detection of genital $\mathrm{TB},{ }^{1}$ but low sensitivity and slow growth of most pathogenic mycobacteria (3 to 6 weeks) results in unacceptable delay in diagnosis. When few mycobacteria are present at the site of infection, multiple cultures may also be necessary to ensure a positive result. Identification of acid-fast organisms in stained smears (AFB smears) may provide rapid diagnosis, but this method requires relatively larger number of bacteria $(>104 \mathrm{ml}$ to be present in the sample. ${ }^{6}$ Serological techniques may be useful in some clinical situations, but both the sensitivity and the specificity of these tests are unsatisfying. ${ }^{7}$

PCR is a technique that shows rapid detection and quantification of few DNA copies with high sensitivity and specificity. Its sensitivity is so high that it requires even less than 10 bacteria/ml of specimen to achieve a positive report. It is a rapid method with results available within a day of the DNA being extracted from the sample. ${ }^{8}$

In the present study, comparative evaluation of direct AFB smear examination, culture in Middlebrook 7H9 media and real-time PCR assay was done for the detection of mycobacteria in various female genital samples.

\section{MATERIALS AND METHODS}

Study design: Hospital-based observational study.

Samples-555 female genital samples like endometrial biopsies (524), fallopian tubes (07), menstrual blood (17) and 
vaginal discharge (07) collected from women of age group 20 to 40 years, presenting with major complaints like primary infertility (450), secondary infertility (38), pain abdomen (20), abortions (15), ectopic pregnancies (07) and menstrual irregularities (25) were processed in the Department of Microbiology, SMS Medical College, Jaipur for detection of mycobacteria by AFB smear, culture on Middlebrook media and real-time PCR using primers based on IS6110 gene.

Sample processing: Endometrial biopsy received in a tube containing normal saline was crushed by means of electric tissue homogenizer for 1 minute, digested and decontaminated by modified Petroff's method by using $2 \% \mathrm{NaOH}$ for 15 minutes, neutralizing with distill water and centrifuged for 20 minutes at $6000 \mathrm{rpm}$ to obtain a pellet. One drop of pellet was used for AFB smear preparation by Ziehl Neelsen method, $200 \mu \mathrm{l}$ for culture on Middlebrook media and $200 \mu \mathrm{l}$ was taken in a separate $1.5 \mathrm{ml}$ Eppendorf tube for DNA extraction.

DNA extraction: DNA extraction was done as per the protocol of QIAGEN QI Amp DNA minicolumn extraction kits (QIAGEN Gmg H, Hilden, Germany). The processed samples were treated with lysozyme, ATL and proteinase $\mathrm{K}$ as per the protocol, for complete homogenization of the tissue and then Buffer AL was added to it.

Ethanol (96 to $100 \%$ ) was added to the sample and whole volume was applied to the QIAamp mini spin column in a $2 \mathrm{ml}$ collection tube without wetting the rim which was centrifuged at $8000 \mathrm{rpm}$ for 1 minute. The mini spin column was then placed in a new $2 \mathrm{ml}$ collection tube and the old one containing the filtrate was discarded. Buffer AW1 was added to it followed by centrifugation at $8000 \mathrm{rpm}$ for 1 minute again. The mini spin column was then placed in a new $2 \mathrm{ml}$ collection tube and the old one containing the filtrate was discarded. Buffer AW2 was added and centrifuged at $14000 \mathrm{rpm}$ for 3 minutes. Finally, the collection tube was replaced by a $1.5 \mathrm{ml}$ Eppendorf and $100 \mu \mathrm{l}$ of AVE was added to it and centrifuged at $8000 \mathrm{rpm}$ for 1 minute. The eluted out DNA was stored at $-20^{\circ} \mathrm{C}$.

\section{DNA Amplification and Detection}

For DNA amplification, master mix was prepared by mixing $25 \mu 1$ of Roche SYBR green master mix (contained SYBR green I, an intercalating dye, Taq DNA polymerase and dUTP), $5 \mu \mathrm{l}$ of forward and reverse primers each and $10 \mu \mathrm{l}$ of nuclease free water in an Eppendorf tube to make a final volume of $45 \mu 1$ per sample, $25 \mu 1$ of sample DNA was added to each tube separately. IS6110 based primers were used to amplify the 123 bp fragment: 5'CCTGCGAGCGTAGGCGTCGC-3' and 5 'CTCGTCCAGCGCCGCTTCGG-3'?
The mix was placed in Roche Cobas Taqman 48 analyzer, cycle included initial cover heating at $100^{\circ} \mathrm{C}$, precycle at $95^{\circ} \mathrm{C}$ for 600 seconds, 45 cycles of denaturation at $95^{\circ} \mathrm{C}$ for 90 seconds, and annealing at $72^{\circ} \mathrm{C}$ for 90 seconds followed by denaturation at $95^{\circ} \mathrm{C}$ for 30 seconds and melting from 60 to $90^{\circ} \mathrm{C}$ and postcycle at $40^{\circ} \mathrm{C}$ for 120 seconds. Positive and negatives controls (autoclaved distill water) were also put along with the samples in each batch. Detection was done by measurement of the SYBR green I fluorescence signal and melting curve analysis of the amplified product in utility channel of the Roche real-time PCR. Positive control M. tuberculosis $\mathrm{H} 37 \mathrm{Rv}$ DNA showed melting peak at $85^{\circ} \mathrm{C} \pm 1 \mathrm{C}$. Melting peak, fluorescence level and the crossing point were taken into consideration for final reporting of test samples. Samples negative by real-time PCR were subjected to spiking with known positive DNA to rule out the presence of PCR inhibitors.

Appropriate precautions were taken to prevent cross contamination, i.e. the well-segregated room's protocol separate rooms for sample collection, sample processing, separate DNA and RNA extraction rooms with class II biosafety cabinets, preparation of master mix (prepared in dedicated laminar flow), amplification, etc. Dedicated pipettes, markers, furniture, etc. were kept for each room.

\section{Culture in Middlebrook}

$100 \mu$ l of the pellet was added to $1 \mathrm{ml}$ Middlebrook $7 \mathrm{H} 9$ media in which $100 \mu \mathrm{l}$ of ADCC was added before hand. Cultures were incubated at $37^{\circ} \mathrm{C}$ for 6 weeks and smears were made at 4 th and 6th week to confirm growth of mycobacteria. Growth was identified as Mycobacterium tuberculosis or nontubercular mycobacteria (NTM) by biochemical tests.

\section{RESULTS}

Out of 555 samples received, a total of $25.22 \%$ (140/555) were positive by the combination of all the methods used. Overall positivity by real-time PCR alone was $23.78 \%$ (132/555), by culture $8.28 \%(46 / 555)$ and $2.70 \%(15 / 555)$ by AFB smear examination. Sample-wise details for the detection of mycobacteria by the three methods are shown in Table 1 .

Out of total positives, $94.28 \%$ (132/140) were positive by the real-time PCR alone, $32.85 \%(46 / 140)$ by culture and $10.71 \%(15 / 140)$ by AFB smear. All the smear-positive samples were positive by culture and PCR, but 08/140 (5.71\%) culture positive samples were negative by both smear as well as PCR, six of which were identified as nontubercular mycobacteria (NTM) by biochemical tests, presence of PCR inhibitors was confirmed in two of these samples by spiking with positive DNA.

\begin{tabular}{llccr}
\multicolumn{5}{c}{ Table 1: Sample-wise details of the methods used to detect mycobacteria } \\
\hline S.no. & Sample type & Smear positivity & Culture positivity & Real-time PCR positivity \\
\hline 1. & Endometrial biopsy (524) & $2.86 \%(15)$ & $8.77 \%(46)$ & $24.61 \%(129)$ \\
2. & Fallopian tube (07) & 0 & 0 & $14.28 \%(01)$ \\
3. & Menstrual blood (17) & 0 & 0 & $11.76 \%(02)$ \\
4. & Vaginal discharge (07) & 0 & 0 & 0 \\
\hline & Total & $2.7 \%(15)$ & $8.28 \%(46)$ & $23.78 \%(132)$ \\
\hline
\end{tabular}


Contamination was observed in 25/555 (4.5\%) samples which were considered negative by culture, three of these were found to be PCR positive. Correlation of smear and PCR positivity with respect to culture is shown in Table 2.

\begin{tabular}{lllc}
\multicolumn{4}{c}{ Table 2: Comparison of the methods used for the detection } \\
of mycobacteria \\
\hline S.No. & Samples (555) & Culture positive & Culture negative \\
\hline 1. & Smear positive & $15(2.70 \%)$ & 0 \\
2. & Smear negative & $31(5.58 \%)$ & $509(91.71 \%)$ \\
3. & PCR positive & $38(6.84 \%)$ & $94(16.93 \%)$ \\
4. & PCR negative & $08(1.44 \%)$ & $420(75.6 \%)$ \\
\hline
\end{tabular}

\section{DISCUSSION}

Endometrial tuberculosis often goes undiagnosed because it is either asymptomatic or presents with nonspecific symptoms in most affected women. Although imaging or hysteroscopy with laparoscopy is not diagnostic, they may raise the index of suspicion and can allow visualization of any pathology. Biopsy of such lesions and demonstration of the causative organism, Mycobacterium tuberculosis, by AFB staining and/ or growth of the organism by culture are mandatory for definitive diagnosis. ${ }^{4}$ In our study the overall detection rate by AFB smear was found to be as low as $2.7 \%$ which also correlates well with other studies done by NV Bhanu et $\mathrm{al}^{4}$ $(1.6 \%), 0.4 \%$ by Agarwal and Gupta ${ }^{10}, 1993$ and $1.23 \%$ by Misra et al, ${ }^{11} 1996$.

Rate of detection by culture was found to be high in our study $8.28 \%$ in comparison to $3.2 \%$ reported by Bhanu et al ${ }^{4}$ however, the rate varies from 3.3 to $10.6 \%$ by Manjunath et $\mathrm{al}^{12}$ Roy et $\mathrm{al}^{2}$ and Srivastava et $\mathrm{al},{ }^{13}$ Kumar et al, ${ }^{14}$ Thangappah et $\mathrm{al}^{15}$ depending on the presence of TB in the patients. Use of liquid culture media may also have contributed to higher culture positivity, liquid culture systems like MGIT 960 have been known to improve the recovery rate of mycobacteria in comparison to Lowenstein Jensen solid media. ${ }^{16}$ In the present study PCR was found to be the most sensitive (94.28\%) method among all the three methods used for the detection of mycobacteria. It was around 9-fold more sensitive than the smear examination (11.11\%) and 3-fold more sensitive than the culture. Bhanu et $\mathrm{al}^{4}$ had reported 14-fold more sensitivity of the PCR in comparison to smear examination. Higher sensitivity of PCR reported by Bhanu et $\mathrm{al}^{4}$ in comparison to our study may be attributed to the lower smear positivity and smaller sample size in their study. Moreover, positivity depends mainly on the sample collection from correct site and presence of TB infection in the tested patient sample.

PCR was found to be superior to culture as culture results were available in 4 to 6 weeks time and only 1 day for PCR. Moreover, 25/555 (4.5\%) samples got contaminated in culture and had to be considered as culture negative but three of these were positive by real-time PCR. However, PCR has its own problems; eight samples were negative by PCR but were positive by culture, six of these were identified as NTM and two had PCR inhibitors. The primers used by us were specific only for Mycobacterium tuberculosis so NTMs were not detected by it. Now with rising incidence of infections due to NTM it is important to also include primers which are genus specific. $^{14}$

$11.07 \%$ of menstrual blood samples were found to be PCR positive, this is an important finding and large scale studies should be done to evaluate utility of menstrual blood vs endometrial biopsy in detecting infection. Even without a comparative evidence and proven sensitivity over biopsy this seems to have practical utility being a noninvasive test and could be used as preliminary screening test.

Molecular diagnosis of genital tuberculosis by real-time PCR has a great potential to improve the clinician's ability to initiate proper treatment which could cure infertility leading to successful pregnancies and positive change in psychology of the patient. But proper precautions need to be taken for carrying on diagnostic PCR to avoid false positive results due to cross contamination though real-time PCR has advantage over the conventional PCR as it is performed in closed tube so risk of contamination is minimized moreover use of enzymes like uracil glycosylase along with dUTP also prevent amplification of old amplicons. Strict protocol of separate and dedicated areas and equipments should be followed for reducing false positives. Moreover, IVD approved/good quality kits should be used for DNA extraction for getting good yield and internal controls should be used to rule out presence of inhibitors which increase negative predictive value of the test. Use of multiplex PCR with genus specific and MTB primers, detection of mRNA instead of DNA which confirms presence of live organism can further help in proper diagnosis of tuberculosis by PCR. A negative TB PCR test can help clinician to investigate other possible etiologies responsible for the medical problem of the patient.

\section{CONCLUSION}

Real-time PCR is a very rapid and sensitive test for diagnosis of genital tuberculosis and has great utility in providing diagnosis in clinically relevant time. However, further improvement can be done in the test by doing multiplex PCR with genus and MTB specific primers to detect all the mycobacteria and including internal controls to rule out PCR inhibitors. Use of newer automated culture systems with PCR can further improve the diagnosis of TB.

\section{REFERENCES}

1. Genital tuberculosis: A diagnostic dilemma. Editorial. J Obstet Gynecol India 2006;56:203-04.

2. Roy A, Mukherjee S, Bhattacharya S, Adhya S, Chakraborty P. Tuberculous endometritis in hills of Darjeeling: A clinicopathological and bacteriological study. Indian J Pathol Microbiol 1993;36:361-69.

3. Parikh FR, Naik N, Nadkarni SG, Soonawala SB, Kamat SA, Parikh RM. Genital tuberculosis: A major pelvic factor causing infertility in Indian women. Fertil Steril 1997;67:497-500.

4. Bhanu NV, Urvashi B, Chakraborty SM, Naga S, Arora J, Rana $\mathrm{T}$, et al. Improved diagnostic value of PCR in the diagnosis of female genital tuberculosis leading to infertility. Journal of Medical Microbiology 2005;54:927-31. 
5. Chakrabarti AK, Sen S, Banerjee A, Roy K. Female genital tuberculosis: A retrospective study. Ind J Tub 1998;45:101.

6. Sjobring U, Mecklenberg M, Andersen AB, Miorneri $\mathrm{H}$. Polymerase chain reaction for detection of Mycobacterium tuberculosis. J Clin Microbiol 1990;28:2200-04.

7. Daniel TM, Debanne SM. The sero-diagnosis of tuberculosis and other mycobacterial diseases by enzyme linked immunosorbent assay. Am Rev Respir Dis 1987;135:1137-51.

8. Eisenstein BL. PCR, a new diagnostic method of using molecular genetics for medical diagnosis. N Eng J Med 1990;322:178-83.

9. Eisenach KD, Cave MD, Bates JH, et al. Detection of Mycobacterium tuberculosis in sputum samples using a polymerase chain reaction. Am Rev Respir Dis 1991;144: 1160-63.

10. Agarwal J, Gupta JK. Female genital tuberculosis: A retrospective clinicopathological study of 501 cases. Indian J Pathol Microbiol 1993;36:389-97.

11. Misra R, Sharma SP, Jina R, Pant N, Srivastava DK. Female genital tract tuberculosis with special reference to sterility in Eastern UP. J Obstet Gynaecol India 1996:104-09.

12. Manjunath N, Shankar P, Rajan L, Bhargava A, Saluja S, Shriniwas. Evaluation of a polymerase chain reaction for the diagnosis of tuberculosis. Tubercle 1991;72:21-27.

13. Srivastava N, Manaktala U, Baveja CP. Role of ELISA (enzymelinked immunosorbent assay) in genital tuberculosis. Int $\mathrm{J}$ Gynaecol Obstet 1997;57:205-06.

14. Kumar P, Shah NP, Singhal A, Chauhan DS, Katoch VM, Mittal $\mathrm{S}$, et al. Association of tubercular endometritis with infertility and other gynaecological complaints of women in India. J Clin Microbiol 2008:46;4068-70.

15. Thangappah RBP, Paramsivan CN, Narayan S. Evaluating PCR, culture and histopathology in the diagnosis of female genital tuberculosis. Indian J Med Res 2011;134:40-46.
16. Rishi S, Sinha P, Malhotra B, Pal N. A comparative study for the detection of mycobacteria by BACTEC MGIT 960, Lowenstein Jensen media and direct AFB smear examination. Indian J Med Micro 2007;25:383-86.

\section{ABOUT THE AUTHORS}

\section{Bharti Malhotra}

Associate Professor and Nodal Officer, Advance Research and TB Lab, Department of Microbiology and Immunology, SMS Medical College, Jaipur, Rajasthan, India

\section{Parul Sinha}

Assistant Professor, Department of Microbiology and Immunology SMS Medical College, Jaipur, Rajasthan, India

\section{Saroj Hooja}

Assistant Professor, Department of Microbiology and Immunology SMS Medical College, Jaipur, Rajasthan, India

\section{Leela Vyas}

Professor and Head, Department of Microbiology and Immunology SMS Medical College, Jaipur, Rajasthan, India

\section{CORRESPONDING AUTHOR}

Bharti Malhotra, C-70, Ram Marg, Tilak Nagar, Jaipur-302004 Rajasthan, India, Phone: 0141-2518639, 0141-2620400, 09414042040 Fax: 01412622899, e-mail-drbhartimalhotra@gmail.com 